\title{
A ORGANIZAÇÃO DO ESPAÇO E DO TEMPO ESCOLAR EM CLASSES MULTISSERIADAS: NA CONTRAMÃO DA LEGISLAÇÃO
}

\author{
Solange Helena Ximenes-Rocha ${ }^{1}$
}

UFOPA

\author{
Maria Lília Imbiriba Sousa Colares ${ }^{2}$
}

UFOPA/UNIR

\section{RESUMO}

A problemática da organização do ensino nas classes multisseriadas tem sido amplamente discutida por pesquisadores brasileiros e estrangeiros, em especial por aqueles que vivenciam a realidade desta forma de organização no meio rural no norte do país. Este artigo tem por objetivo discutir na literatura a organização do espaço e do tempo nas classes multisseriadas, tendo como objeto de análise uma pesquisa com abordagem descritivo-analítica de natureza qualitativa desenvolvida no Estado do Pará envolvendo quatro professoras que atuavam em classes multisseriadas. Durante a coleta de dados realizou-se entrevistas com as professoras e observação das aulas por um semestre letivo. Neste texto se utilizam as observações realizadas como principal fonte de dados. Notou-se nas classes multisseriadas que o tempo efetivamente dedicado a cada série é infinitamente menor que o recomendado pela legislação, embora as professoras cumpram os duzentos dias letivos preconizados pela LDBEN. Conclui-se indicando que tal problemática parece invisível aos gestores das políticas públicas e aos legisladores e caminha na contramão do que prevê a legislação educacional brasileira.

Palavras-chave: Classes multisseriadas; Escola do campo; Política educacional.

\section{THE ORGANIZATION OF SPACE AND TIME IN SCHOOL MULTIGRADE CLASSES: OPPOSITE THE LAW}

\begin{abstract}
The problem of the organization of teaching in multigrade classes has been widely discussed by Brazilian and foreign researchers, especially for those who experience the reality of this form of organization in rural areas in the north of Brazil. This article discuss the literature on the organization of space and time in multigrade classes, adopting as object of analysis a qualitative research developed in the Para State involving four teachers who worked in multigrade classes. During the data collection was carried out interviews with teachers, and observation of classes for a semester. For this article we use the observations as the main data source. It was noted in multigrade classes than the time actually devoted to each series is infinitely smaller than recommended by legislation, although the teachers meet the two hundred school days recommended by educational legislation. We conclude indicating that this problem seems invisible to public policy makers and legislators and walks in the opposite direction that provides for the Brazilian educational legislation.
\end{abstract}

Keywords: Multigrade classes; rural school, educational policy 


\section{Introdução}

A educação do campo tem conquistado espaço no debate acadêmico nacional principalmente a partir da década de 90 do século XX quando houve importantes conquistas dos movimentos sociais organizados em defesa de uma escola que atendesse às demandas dos povos trabalhadores do meio rural. Até então parecia haver um consenso sobre a educação rural e diríamos mesmo uma aceitação pacífica de sua inferioridade em relação à educação urbana. Com os avanços teóricos na área as práticas de transposição do currículo urbano para o meio rural passaram a ser categorizadas como urbanocêntricas e questionadas.

Desse modo, diferentes pesquisadores (HAGE, 2005; CALDART, 2000; BEZERRA NETO, 1999) tem se debruçado sobre a problemática da escola do campo a saber: as classes multisseriadas; a educação do campo e os movimentos sociais do campo; os fundamentos teóricos e metodológicos presentes nas práticas dos educadores do meio rural, entre outros.

No que tange à questão das classes multisseriadas o trabalho de Hage (2005) tem se destacado e apresentado importantes contribuições para o debate. Dentre suas principais preocupações se destaca a necessidade de garantia dos parâmetros de qualidade do ensino público conquistados pelos movimentos sociais e suas relações com os marcos operacionais preconizados pela legislação educacional brasileira.

Ao tratar do ensino no meio rural Hage indica que "apesar de concentrar mais da metade das escolas brasileiras, [...] a metade das escolas do campo ainda é de uma sala e 64\% são multisseriadas" (2005, p. 44). Segundo dados do Censo Escolar de 2003 o Estado da Bahia era o maior em número de turmas multisseridas com 21.451 e o Estado do Pará era o segundo colocado com 11.231 turmas multisseriadas (INEP, 2003). No Pará a organização em turmas multisseriadas constitui a modalidade predominante da oferta do primeiro segmento do ensino fundamental atendendo $97,45 \%$ da matrícula nessa etapa escolar (HAGE, 2005).

Grande parte dos pesquisadores que se refere às escolas localizadas no meio rural caracterizam-nas como carentes. São apontados: a precariedade da estrutura física das escolas; as longas distâncias percorridas por professores e alunos para chegar até a escola; a dificuldade de acesso à merenda escolar; a baixa qualificação dos professores e o currículo urbanocêntrico (PEREIRA, 2005).

Neste artigo apresentamos alguns elementos que permitem melhor compreender a problemática da organização do espaço e do tempo nas classes multisseriadas. Antes de tratar diretamente da temática, pretendemos mostrar, em breves palavras, o panorama das classes multisseriadas na escola do campo.

\section{As classes multisseriadas na escola do campo}

A luta por uma educação do campo originou-se para denunciar o descaso e o silenciamento que historicamente envolveu a educação dessa população. Esse silenciamento das ações governamentais não aconteceu somente no aspecto educacional, mas também na saúde, na habitação, no saneamento básico, entre outros. Mas, o 
movimento por uma educação do campo não fica apenas na denúncia, destaca o que há de mais perverso nesse esquecimento: o direito à educação que foi negado a essa população. Foram direitos usurpados, negados (CALDART, 2009, p. 9).

Não identificamos um marco histórico que indica quando iniciaram as classes multisseriadas no Brasil. Todavia, é possível inferir, que a existência de tal forma de organização, está estritamente vinculada ao projeto de desenvolvimento econômico adotado pelo Brasil e sua política agrícola. Atualmente há um privilégio do agronegócio para atender ao mercado global e uma marginalização da agricultura familiar. Assim, para manter o homem no campo, qualquer escola, qualquer educação serve.

$\mathrm{Na}$ consolidação desta ideologia o ruralismo pedagógico surgiu como uma das primeiras propostas oficiais para a educação do campo e, formalizada na primeira década do século XX, reforçava a ideia de que a educação deveria servir para fixar o homem ao campo. Tal movimento previa a alteração e adaptação dos currículos e programas à realidade do campo.

O ruralismo pedagógico propugnava uma escola integrada às condições locais, regionalista, cujo objetivo maior era promover a "fixação" do homem ao campo (MAIA, 1982, p.05). Camuflava, no entanto, o caráter político e ideológico usando a questão educacional como bandeira de luta.

Ainda conforme Maia (op. cit), o ruralismo pedagógico, comprometido com a manutenção do 'status quo', contribui para uma percepção viesada da contradição cidadecampo como algo 'natural', concorrendo consequentemente para sua perpetuação. Dessa forma, conclui que a grande missão do professor rural seria de demonstrar as 'excelências' da vida no campo, convencendo o homem a permanecer marginalizado dos benefícios da civilização urbana (1982, p. 06).

Contrariamente ao que afirma NAGLE, ao dizer que o processo de ruralização do ensino apresentava um ideário que apenas parcialmente influenciou a legislação escolar e as práticas escolares $(1974$, p. 233) temos percebido forte retomada do discurso ruralista nas práticas educativas pensadas para o meio rural.

No contexto das classes multisseriadas é possível citar o Programa Escola Ativa que tem como objetivos: apoiar os sistemas estaduais e municipais de ensino na melhoria da educação nas escolas do campo com classes multisseriadas, fornecendo diversos recursos pedagógicos e de gestão; fortalecer o desenvolvimento de propostas pedagógicas e metodológicas adequadas a classes multisseriadas; realizar a formação continuada para os educadores envolvidos no programa em propostas pedagógicas e princípios políticos pedagógicos voltados às especificidades do campo; fornecer e publicar materiais pedagógicos que sejam apropriados para o desenvolvimento da proposta pedagógica.

Recentemente foi lançado pelo governo federal o PRONACAMPO que visa estabelecer um conjunto de ações articuladas para atender escolas do campo e quilombolas. A proposta está articulada em quatro eixos assim denominados: gestão e práticas pedagógicas, formação de professores, educação de jovens e adultos e educação profissional e tecnológica.

Nos dois programas citados como exemplos há elementos comuns que envolvem a formação dos professores, gestão, metodologias de ensino/práticas pedagógicas e um objetivo implícito de assegurar a adequação das ações pedagógicas às especificidades do 
campo para garantir a permanência do homem do campo em seu lugar de origem o que no PRONACAMPO está explicitado via cursos de formação profissional para os jovens e adultos. Acrescenta-se ainda que os programas pensados para o meio rural reduzem a problemática das escolas do campo ao fazer pedagógico e/ou à qualificação dos professores como se as metodologias propostas fossem suficientes para alterar o cenário educacional atual.

Observa-se assim, que o alcance do ideário ruralista está para além do que NAGLE apontava na década de 1970 e que atualmente passa a ser assumido nas propostas pensadas pelos movimentos sociais do campo para as escolas do meio rural como bem indica Bezerra Neto (1999). É preciso lutar por uma política de educação que seja acessível a todos, de modo que os alunos filhos das classes trabalhadoras, na cidade ou no campo, tenham acesso aos saberes universais produzidos socialmente.

\section{A organização do espaço e tempo escolar nas classes multisseriadas}

Nesta sessão do artigo adota-se, como recurso didático, a definição e breve caracterização das turmas multisseriadas e em seguida faz-se a descrição de observações realizadas durante pesquisa do Grupo de Estudos e Pesquisas Formação de Professores na Amazônia Paraense - FORMAZON, para contextualizar a problemática apresentada.

As classes multisseriadas caracterizam-se por reunir em um mesmo espaço físico diferentes séries que são gerenciadas por um mesmo professor. São, na maioria das vezes, única opção de acesso de moradores de comunidades rurais (ribeirinhas, quilombolas) ao sistema escolar. As classes multisseriadas funcionam em escolas construídas pelo poder público ou pelas próprias comunidades, ou ainda em igrejas, barracões comunitários, sedes de clubes, casas dos professores entre outros espaços menos adequados para um efetivo processo de ensino-aprendizagem.

As professoras - por vezes alguns homens assumem as classes, mas são minoria possuem escolaridade abaixo da recomendada pela legislação e na ausência de políticas de formação se responsabilizam por seus processos de qualificação profissional arcando inclusive com as despesas provenientes de tal investimento. Santos (2012) identificou no município de Santarém no Oeste Paraense que os professores com a menor qualificação são lotados preferencialmente nas escolas do meio rural.

A carência de materiais didáticos também compromete a qualidade do trabalho docente e a adaptação de materiais inusitados para uso didático é frequente. As professoras utilizam pedras, grãos de cereais, folhas para fazer tintura, produzem cola caseira entre outros materiais que ao mesmo tempo em que favorecem uma aproximação com a realidade local, o exercício da experiência (Dewey, 1971) e o uso sustentável dos recursos naturais existentes na comunidade limitam o tempo de efetivo trabalho em sala de aula como preconiza a LDB 9394/96 no artigo 34. Quando as professoras não ocupam o tempo das aulas com a confecção de tais materiais é porque utilizaram seu tempo de descanso para prepará-los já que não há remuneração pelo trabalho extra realizado. Tal situação implica no processo de precarização do trabalho docente. A esse respeito, Fernandes; Orso (2013) defendem que: 
[...] a luta pela superação da pauperização e precarização do trabalho docente, portanto, passa também pela superação da condição de proletário do docente, pela sua emancipação, pela emancipação de toda classe trabalhadora. Esta é a melhor maneira de contrapor-se à discriminação e ao rebaixamento do ensino das camadas populares. Professores desproletarizados, emancipados, também produzem uma educação emancipada ( $\mathrm{p}$. $13)$.

Assim, além da desproletarização e superação da precarização do trabalho docente, o trabalho em classes multisseriadas apresenta ainda um grande desafio aos docentes uma vez que há carência de um saber sistematizado e reconhecido pela academia que oriente a atuação nesse espaço. Observa-se que parece existir uma negação do fazer pedagógico da multisserie e a complexidade que o envolve.

Destaca-se ainda nas classes multisseriadas as formas de organização do espaço e do tempo escolar. Quanto à organização do espaço parece haver um consenso entre as professoras, aprendido pela observação (LORTIE, 1975), de que é necessário separar os alunos por "séries" uma vez que facilitaria o trabalho docente. Separados em séries ficaria mais fácil lidar com as demandas discentes, todavia nega-se o potencial criativo que a interação e a troca de experiências entre os alunos possibilitaria.

Outro aspecto a ser destacado é que a lógica da seriação, presente no modelo tradicional de escolarização, impõe aos educadores do campo a obrigatoriedade de elaborar um planejamento específico para cada série, uma vez que prevalece a orientação burocrático-administrativa de pertencimento dos alunos a um regime seriado de ensino.

No que diz respeito às formas de organização do tempo estas não diferem muito da lógica da seriação. Há escolas em que os professores dividem o tempo por séries, dedicando as duas primeiras horas do dia para $3^{\mathrm{a}}$ e $4^{\mathrm{a}}$ série e as duas últimas horas para a $1^{\mathrm{a}}$ e $2^{a}$ série, por exemplo. Há professores que dividem as turmas no espaço disponível na sala, todavia não dedicam um tempo específico para cada uma, na verdade vão atendendo os alunos conforme as demandas ou em regime de rodízio.

Dentre as professoras participantes deste estudo ${ }^{3}$ a distribuição do espaço e tempo guarda peculiaridades. No que tange ao tempo dedicado para a exposição da matéria a professora Iara faz a divisão dependendo da temática a ser explicada. Informa que às vezes trabalha o mesmo conteúdo para séries diferentes aumentando o grau de complexidade do tema. A professora Ceci não deixou claro o cronograma de trabalho e o tempo dedicado a cada série depende do desempenho dos alunos, todavia foi possível observar que a mesma dedica a maior parte do tempo aos alunos da $1^{\mathrm{a}}$ série. As professoras Juçara e Iracema fazem rodízios entre as séries que duram em média vinte minutos ou o tempo necessário para concluir uma explicação ou correção de exercícios.

No que tange à organização do espaço há duas variações significativas: a que alterna a separação em séries e a distribuição aleatória dos alunos na classe distribuídos em círculos ou em fileiras.

Dentre as professoras pesquisadas observou-se que adotavam como estratégia de organização do espaço e tempo escolar a mesma lógica das escolas urbanas, dividindo os alunos por série e fazendo um atendimento em forma de rodízio entre as turmas. $\mathrm{Na}$ aula 
de uma das professoras observamos uma situação que nos chamou muito a atenção e que passamos a relatar a seguir.

Durante a pesquisa observou-se que a ausência de uma divisão do tempo para cada turma fez com que a professora só pudesse dar atenção aos alunos da $2^{\mathrm{a}}$ série cerca de uma hora depois que a aula havia começado. Foi alertada pelo apelo de uma aluna que falou: "professora, vem fazer pra gente". O chamado da aluna alertou a pesquisadora que estava na sala que passou a cronometrar o tempo dedicado pela professora a cada série a partir daquele momento. Eram 13h50min quando se começou a contar o tempo. Naquele dia, a professora dedicou 33 minutos para a $1^{\text {a }}$ série, 21 minutos para a $2^{\mathrm{a}}$ série, 52 minutos para a $3^{\mathrm{a}}$ série e fez 21 minutos de intervalo (XIMENES-ROCHA, p. 112-3, 2007).

Ao relatar este fato nosso desejo é chamar a atenção para a organização do tempo nas classes multisseriadas e confrontá-lo com o que estabelece a legislação na perspectiva de tecer um diálogo sobre tal problemática nas escolas do meio rural.

A Lei de Diretrizes e Bases da Educação Nacional - LDBEN preconiza no Capítulo II da Educação Básica, Seção I das Disposições Gerais, Artigo 23, Parágrafo $2^{\circ}$ que o calendário escolar deverá adaptar-se às peculiaridades locais, inclusive climáticas e econômicas, a critério do respectivo sistema de ensino, sem com isso reduzir o número de horas letivas previsto nesta Lei. No Artigo 24, item 1 da mesma LDBEN fica estabelecido que a carga horária mínima anual será de oitocentas horas, distribuídas por um mínimo de duzentos dias de efetivo trabalho escolar, excluído o tempo reservado aos exames finais, quando houver e, na seção III que trata do ensino fundamental em seu Artigo 34 que a jornada escolar no ensino fundamental incluirá pelo menos quatro horas de trabalho efetivo em sala de aula, sendo progressivamente ampliado o período de permanência na escola.

Notou-se nas classes multisseriadas que o tempo efetivamente dedicado a cada série é infinitamente menor que o recomendado pela legislação, embora as professoras cumpram os duzentos dias letivos. Situação semelhante foi identificada na pesquisa realizada por Barros (2005):

Verificamos que como frequentemente as escolas não possuem espaços adequados e condizentes com a quantidade de alunos, os educadores acabam dividindo os horários de aula para trabalharem duas horas iniciais (07 às 09:30h) com a $1^{\mathrm{a}} \mathrm{e}$ a $2^{\mathrm{a}}$ série e as outras duas horas $(09: 30 \mathrm{~h}$ às 11:30 h) com a $3^{\mathrm{a}}$ e a $4^{\mathrm{a}}$ séries (p.148).

Tal problemática parece invisível aos gestores das políticas públicas e aos legisladores. Se a recomendação preconizada na Lei de Diretrizes e Bases da Educação Nacional fosse realmente cumprida a forma de organização em classes multisseriadas teria que ser revista uma vez que, na melhor das hipóteses, apenas $1 / 3$ do tempo escolar que deveria ser dedicado para cada série é cumprido.

A política da Escola Ativa inspirada no modelo colombiano, visa responder às problemáticas acima explicitadas e tem como foco a questão metodológica para o trabalho pedagógico em classes multisseriadas. Todavia o "pacote" ao ser implementado na 
Amazônia brasileira descaracteriza a identidade local e reduz os professores a meros executores de um currículo prescrito sem a participação dos docentes e discentes no processo de planejamento.

Deste modo, torna-se urgente a criação de políticas públicas que atendam à educação do campo. Referimo-nos a políticas que reforcem a riqueza e a diversidade dos que vivem no campo. Portanto, segundo Cardart (2009), são necessárias, políticas específicas que possam romper com o longo processo de exclusão e discriminação, assim como proporcionar a garantia de sua escolarização nos lugares onde nasceram e vivem.

Nesse sentido, no artigo sobre A Importância do Materialismo Histórico na Formação do Educador do Campo, Bezerra Neto e Bezerra (2010) discordam que uma pedagogia específica para o homem do campo possa contribuir para a sua fixação no meio rural. Para eles, "o que realmente pode prender o homem à terra são as condições econômicas e as políticas implementadas para o setor e não a pedagogia" (2010, p. 257). Assim, acreditamos que somente as relações econômicas mediadas pela política podem possibilitar a permanência desses sujeitos no campo, com a conquista da terra, dos equipamentos agrícolas e das condições de sobrevivência favoráveis a sua manutenção.

\section{Considerações Finais}

Entendemos que a problemática da escola do campo no Brasil é histórica e os estudos de Leite (1999), Calazans (1993), Caldart (2009), entre outros, nos auxiliam nesta compreensão. Estes estudiosos indicam que não há como compreender tal realidade sem entender o papel do Estado e sua omissão histórica com o processo de escolarização dos homens que habitam o meio rural.

Acreditamos que as classes mutisseriadas são importantes mecanismos de escolarização dos moradores do meio rural, todavia precisam ser repensadas. Há estudos, podemos citar entre eles (HAGE, 2005), que indicam que elas representam muitas vezes a única forma de presença do Estado no campo já que há ausência de saneamento básico, atendimento de saúde entre outros.

Porém, em que pese a importância das turmas multisseriadas para a libertação das populações camponesas por meio da apropriação do saber escolarizado, não é possível negar as problemáticas que as envolvem muito menos o estado de precariedade a que estão submetidas.

Entendemos que o conhecimento necessário para o empoderamento das populações ribeirinhas, quilombolas, do campo e da floresta deve passar, necessariamente, por um saber sistematizado de qualidade, com professores qualificados e infraestrutura adequada. A presente pesquisa apresenta uma das pontas deste "iceberg", no fundo há muitas outras questões que merecem ser estudadas e desveladas.

\section{Referências}

BARROS, O. F. A Organização do Trabalho Pedagógico das Escolas Multisseriadas: Indicativos de saberes pedagógicos de resistência educacional no campo in: HAGE, Salomão Mufarrej (org.). Educação do campo na Amazônia: retratos de realidade das escolas multisseriadas no Pará. Belém: Gráfica e Editora Gutemberg Ltda, 2005. 
BEZERRA NETO, L. Sem-terra Aprende e Ensina: Estudo sobre as práticas educativas do Movimento dos Trabalhadores Rurais. Campinas: Autores Associados, 1999.

BEZERRA NETO, L.; BEZERRA, M. C. dos S. A importância do materialismo histórico na formação do educador do campo. Revista HISTEDBR on-line. Campinas, ago. 2010, número especial, p. 251-272.

BRASIL/MEC. Lei 9.394, de 20 de dezembro de 1996. Lei de Diretrizes e Bases da Educação Nacional (LDBEN). Brasília, 1996.

CALAZANS, M. J. C. Para Compreender a Educação do Estado no Meio Rural - Traços de uma Trajetória. In: Educação e Escola no Campo. Campinas: Papirus, 1993.

CALDART, R. S. Pedagogia do Movimento Sem-Terra. Petrópolis: Vozes, 2000.

CALDART, Roseli Salete. Primeira Conferência Nacional por uma Educação Básica no Campo. In: ARROYO, M. G. et alii (Org). Por uma Educação do Campo. 4. ed. Petrópolis, RJ: Vozes, 2009.

DEWEY, J. Experiência e Educação. São Paulo. Ed. Nacional. 1971.

FERNANDES, H. C.; ORSO, P. J. O trabalho Docente: pauperização, precarização e proletarização. Disponível em: http://www.histedbr.fae.unicamp.br/acer_histedbr/jornada/jornada9/_files/PyzH1GvQ.pdf. Acesso em: 04.04.2013

HAGE, S. M. (org.). Educação do campo na Amazônia: retratos de realidade das escolas multisseriadas no Pará. Belém: Gráfica e Editora Gutemberg Ltda, 2005.

LEITE, C.. O lugar da escola e do currículo na construção de uma educação intercultural. In: CANEN, A. \& MOREIRA, A. F. (orgs.). Ênfases e Omissões no Currículo. Campinas, SP: Papirus, 2001. Ministério da Educação/Fundescola. Escola Ativa: capacitação de professores. Brasília, 1999.

LORTIE, D. C. Schoolteacher: a sociologial study. Phoenix Edition, USA, 1975.

MAIA, E. M. Educação Rural no Brasil: o que mudou em 60 anos? ANDE. Ano 01. $n^{\circ}$ 03, 1982.

NAGLE, J. Educação e Sociedade na Primeira República. São Paulo: EPU/Ed. da Universidade de São Paulo. 1974.

PEREIRA, A. C. da S. Lições da educação do campo: Um enfoque nas classes multisseriadas. In HAGE, Salomão Mufarrej (org.). Educação do campo na Amazônia: retratos de realidade das escolas multisseriadas no Pará. Belém: Gráfica e Editora Gutemberg Ltda, 2005.

XIMENES-ROCHA, S. H. Construção da ação docente: aprendizagens de professoras leigas em classes multisseriadas na escola do campo. Tese de Doutorado. São Carlos. UFSCAR. 2007. 


\section{Notas:}

${ }^{1}$ FORMAZON/HISTEDBR-UFOPA Email: Solange.ximenes@ gmail.com

${ }^{2}$ LAPPLANE/UNICAMP. HISTEDBR-UFOPA. PPGE UNIR Email: lilia.colares@ hotmail.com

${ }^{3}$ As professoras selecionadas eram experientes com um tempo de serviço médio em torno de 20 anos. São, neste estudo, denominadas de Iara, Juçara, Ceci e Iracema. Fez-se a opção por esses nomes por apresentarem estreita relação com a história da região amazônica, marcada pela forte influência da cultura indígena e pela luta vivenciada por uma das professoras em ver demarcada uma área indígena pertencente à comunidade na qual mora e onde está localizada a escola.

Recebido em abril-13

Aprovado em maio-13 